\title{
Perspective
}

\section{Neuronal nicotinic acetylcholine receptors are important targets for alcohol reward and dependence}

\author{
Jie $\mathrm{WU}^{1,2, *}$, Ming $\mathrm{GAO}^{2}$, Devin H TAYLOR ${ }^{2}$ \\ ${ }^{1}$ Ningbo University Medical School, Ningbo 315211, China; ${ }^{2}$ Division of Neurology and Neurobiology, Barrow Neurological Institute, St \\ Joseph's Hospital and Medical Center, Phoenix, Arizona 85013-4409, USA
}

\begin{abstract}
Neuronal nicotinic acetylcholine receptors are important targets for alcohol reward and dependence. Alcoholism is a serious public health problem and has been identified as the third major cause of preventable mortality in the world. Worldwide, about 2 billion people consume alcohol, with 76.3 million having diagnosable alcohol use disorders. Alcohol is currently responsible for the death of $4 \%$ of adults worldwide (about 2.5 million deaths each year), and this number will be significantly increased by 2020 unless effective action is taken. Alcohol is the most commonly abused substance by humans. Ethanol (EtOH) is the intoxicating agent in alcoholic drinks that can lead to abuse and dependence. Although it has been extensively studied, the mechanisms of alcohol reward and dependence are still poorly understood. The major reason is that, unlike other addictive drugs (eg, morphine, cocaine or nicotine) that have specific molecular targets, EtOH affects much wider neuronal functions. These functions include phospholipid membranes, various ion channels and receptors, synaptic and network functions, and intracellular signaling molecules. The major targets in the brain that mediate EtOH's effects remain unclear. This knowledge gap results in a therapeutic barrier in the treatment of alcoholism. Interestingly, alcohol and nicotine are often co-abused, which suggests that neuronal nicotinic acetylcholine receptors (nAChRs), the molecular targets for nicotine, may also contribute to alcohol's abusive properties. Here, we briefly summarize recent lines of evidence showing how EtOH modulates nAChRs in the mesolimbic pathway, which provides a perspective that nAChRs are important targets mediating alcohol abuse.
\end{abstract}

Keywords: alcoholism; abused substance; ethanol reward and dependence; smoking; nicotine; nicotinic acetylcholine receptor; mesolimbic dopamine system

Acta Pharmacologica Sinica (2014) 35: 311-315; doi: 10.1038/aps.2013.181; published online 27 Jan 2014

\section{Introduction}

Alcoholism is a serious public health problem and has been identified as the third major cause of preventable mortality in the world ${ }^{[1]}$. Approximately 2 billion people worldwide consume alcohol, with 76.3 million who have diagnosable alcohol use disorders (AUDs). Alcohol is currently responsible for the deaths of $4 \%$ of the world's adult population (about 2.5 million deaths each year), and this number will increase by 2020 unless effective action is taken ${ }^{[2]}$. Economically, in 2005, more than $\$ 200$ billion of the total United States. healthcare cost was attributable directly to the productivity impacts of alcohol, such as lost wages, which were significantly higher than cancer ( $\$ 196$ billion) or obesity (\$133 billion) ${ }^{[3]}$. Thus, there is an urgent need to reduce the global rate of AUDs. Unfortunately, attempts to combat alcohol abuse have been severely confounded.

\footnotetext{
* To whom correspondence should be addressed.

E-mail Jie.Wu@DignityHealth.org

Received 2013-10-07 Accepted 2013-12-18
}

Alcohol is the most commonly abused substance by humans. Ethanol $(\mathrm{EtOH})$ is the intoxicating agent in alcoholic drinks that can lead to abuse and dependence ${ }^{[4]}$. Alcohol use has been ascribed both positive and negative effects. While alcohol at low doses has been shown to provide cardiovascular protection $^{[5]}$, binge drinking is associated with higher incidents of cardiovascular disease and associated mortality ${ }^{[6]}$. Projections from the ventral tegmental area (VTA) to the nucleus accumbens (NAc), by way of the medial forebrain bundle, make up a vital component of the mesolimbic pathway ${ }^{[7]}$. The rewarding effects of EtOH have been linked to the mesolimbic dopamine (DA) system ${ }^{[7]}$, wherein an increase in DA in the NAc is thought to be vital for reward signaling. This system has been connected to the rewarding effects of many abused drugs. However, unlike other addictive drugs (eg, morphine, cocaine or nicotine) which have specific molecular targets, EtOH affects much wider neuronal functions including phospholipid membranes, various ion channels and receptors, synaptic and network functions, and intracellular signaling molecules ${ }^{[8]}$. Although it has been extensively investigated 
(especially in $\mathrm{GABA}_{\mathrm{A}}$ receptors ${ }^{[9]}$ ), the major target mediating $\mathrm{EtOH}$ reward signaling and the precise mechanisms of $\mathrm{EtOH}$ reward and dependence are still poorly understood ${ }^{[10]}$. This gap in knowledge results in a therapeutic barrier in the treatment of alcoholism.

It is well known that alcohol and nicotine are often coabused. The number of alcoholics who also smoke has been reported to be as high as $96 \%{ }^{[11]}$, suggesting that neuronal nicotinic acetylcholine receptors (nAChRs), the molecular targets of nicotine, may contribute to the abusive properties of alcohol. Mounting genetic, pre-clinical, and clinical evidence demonstrates that EtOH directly and indirectly modulates $\mathrm{nAChR}$ function in the mesolimbic pathway, which may underlie alcohol reward and dependence. These lines of evidence also build the rationale that $\mathrm{nAChRs}$ are likely important targets which mediate alcohol abuse. However, a consensus is yet to emerge as to which nAChR subtype critically mediates EtOH's central effects.

\section{Impact of $\mathbf{n A C h R s}$ in EtOH reward and dependence}

$\mathrm{nAChRs}$ are ligand-gated ion channels expressed in a variety of compositions with two subtypes, $a$ and $\beta$. Nine types of $a$ subunits ( $\alpha 2-a 10)$ are known to be expressed in vertebrates, as well as three $\beta$ subunit types $(\beta 2-\beta 4)^{[12]}$. The pentameric structure of each individual $\mathrm{nAChR}$ determines the variety of ion that is able to pass through the receptor's channel ${ }^{[12]}$. For example, the a $4 \beta 2$ receptor mostly permits the passage of sodium through its pore while the a7 receptor permits sodium passage and allows relatively high calcium permeability $^{[12]}$. The known subunits found in the human brain are thought to be $\alpha 3-\alpha 7, \beta 2$, and $\beta 4$, although not all are presently known ${ }^{[12,13]}$. The most common nicotinic pentamers in the human brain consist of heteromeric $\alpha 4$ and $\beta 2$ subunits or $\alpha 7$ subunits ${ }^{[14]}$. These pentamers could be joined as $a 4_{(2)} \beta 2_{(3)}, \alpha 4_{(3)}$ $\beta 2_{(2)}$, or homomeric a7 receptors. nAChR a6 subunits are not widely expressed in the brain, but are prevalent in midbrain DAergic regions associated with pleasure, reward, and mood control $^{[15]}$, suggesting that $a 6^{*}$-nAChRs play critical roles in nicotine dependence and in the ability to modulate mood and emotion attributed to nicotine ${ }^{[16]}$.

The concept that $\mathrm{nAChRs}$ are important targets in the mediation of EtOH reward and dependence is built on the pharmacological blockade of EtOH reward and dependence in a variety of alcoholic animal models by a nAChR antagonist mecamylamine. For instance, systemic mecamylamine significantly reduces EtOH-mediated extracellular DA release in the NAc ${ }^{[17]}$, and reduces EtOH consumption in rats ${ }^{[18]}$. Local injection of mecamylamine into the VTA reduces rat operant responding for $\mathrm{EtOH}$ and $\mathrm{EtOH}$-associated cues, as well as consumption during relapse ${ }^{[19,20]}$. Mecamylamine delivered systemically reduces EtOH consumption in C57Bl/6J mice in restricted access EtOH consumption "drinking in the dark" (DID) paradigm ${ }^{[21]}$, a model of binge drinking, as well as in the two-bottle choice consumption assay ${ }^{[22]}$. More recently, it has been demonstrated that mecamylamine blocks EtOHmediated activation of VTA DAergic neurons in mouse mid- brain slices $^{[23]}$. Mecamylamine also blocks the ability of EtOH condition place preference in mice ${ }^{[24]}$. Since mecamylamine is a non-specific nAChRs blocker, it usually blocks all nAChR subtypes except a7-nAChRs at the doses used in these studies. Thus, the effects of $\mathrm{nAChR}$ subtype special antagonists on EtOH-induced reward, dependence and consumption have been examined. Unfortunately, neither the a $4 \beta 2 \mathrm{nAChR}$ antagonist dihydro- $\beta$-erythroidine $(\mathrm{DH} \beta \mathrm{E})$ nor the $\alpha 7 \mathrm{nAChR}$ antagonist methyllycaconitine (MLA) reduce $\mathrm{EtOH}$-mediated DA release in the NAc, EtOH intake or consumption ${ }^{[20,25]}$. On the other hand, the $\mathrm{AAChR}$ antagonist a-conotoxin MII, which blocks $a 3 \beta 2^{*}, \beta 3^{*}$ and $a 6^{*}$ subtypes, inhibits EtOH consumption, operant responding, and DA release in the NAc of $\operatorname{rats}^{[20,26]}$. This pharmacological data suggest that both $\alpha 4 \beta 2$ and $a 7 \mathrm{nAChR}$ subtypes may not be critical for ethanol reward and consumption behavior, while $a 6^{*}$ and/or a $3^{*} \mathrm{nAChR}$ subtypes are likely important targets for these EtOH-induced behavioral alterations.

Further studies using $\mathrm{nAChR}$ subunit knock out $(\mathrm{KO})$ mice show that $\mathrm{nAChR} \beta 2$, a5*, a $6^{*}$, or a7 KO mice exhibit similar EtOH consumption behavior to WT mice ${ }^{[27-29]}$. Interestingly, in a6 and a5, but not $\beta 3, \mathrm{KO}$ mice, high doses of EtOH-induced sedation was enhanced ${ }^{[28,29]}$. In addition, a $4 \mathrm{KO}$ mice show significantly less acute EtOH consumption to high (20\%) but not low (2\%) concentrations of $\mathrm{EtOH}^{[30]}$. Considering nAChR subunit compensation in a nAChR KO mouse background, these results collected from $\mathrm{nAChR}$ KO mice will need to be verified using shRNAs to knock-down nAChR subunits in discreet brain regions, and these data must also be interpreted with pharmacological evidence.

Finally, recent accumulating evidence suggests that common genes may influence the development of alcohol and nicotine behaviors individually, and contribute to both disorders in humans ${ }^{[31]}$. For example, the mammalian genes that code for the a6 and $\beta 3$ subunits of the nAChRs (Chrna6 and Chrnb3, respectively) are located adjacent to one another on human and mouse chromosome 8 . These two subunits have gained special attention for their expression in the VTA, their mRNA increase in the VTA after acute exposure to $\mathrm{EtOH}^{[30]}$, and their roles in regulating $\mathrm{EtOH}$-induced increase in DA release $^{[26]}$. More importantly, human genetic studies have shown that variation in these genes is associated with alcohol phenotypes $^{[32]}$. These lines of evidence suggest that the $a 6^{*}$ and $\beta 3^{*} \mathrm{nAChRs}$ may modulate alcohol behaviors. Collectively, mounting lines of evidence suggest that various $\mathrm{AChR}$ subtypes are involved in alcohol reward and dependence ${ }^{[33]}$. Although having very limited investigation, the $a 6^{*} \mathrm{nAChRs}$ in the VTA have attracted special attention ${ }^{[33]}$ (Figure 1).

\section{Cellular mechanisms of nAChR-mediated EtOH reward and dependence}

Neuronal nAChRs mediate cholinergic modulations in brain function through both pre- and post-synaptic mechanisms. Most nAChRs in the central nervous system are located on presynaptic terminals/boutons ${ }^{[34,35]}$, where they modulate various neurotransmitter releases ${ }^{[36]}$, including acetylcholine 

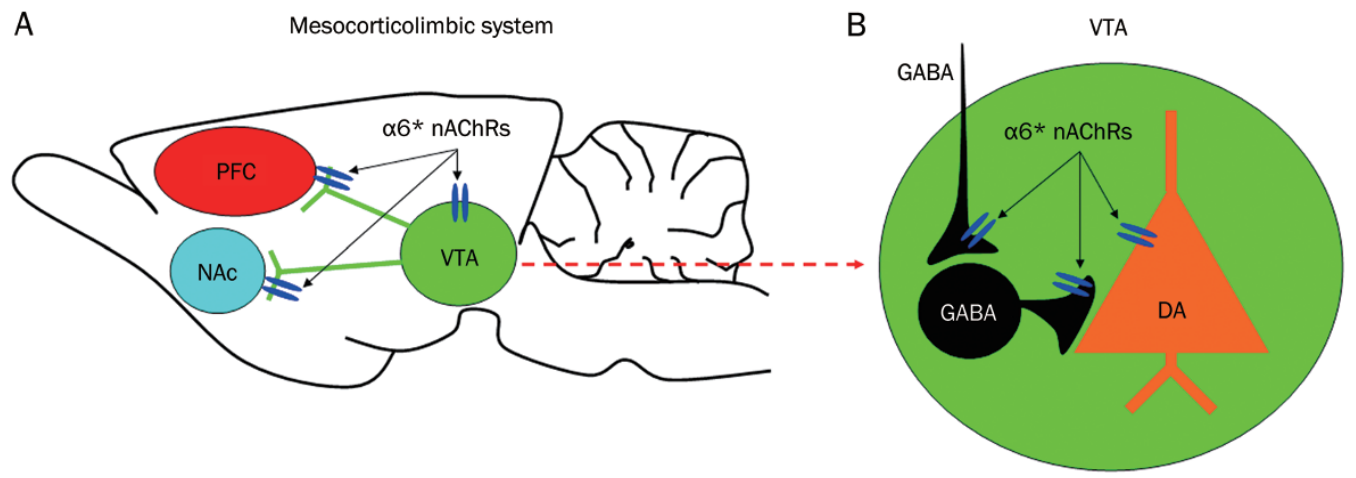

Figure 1. $\alpha 6^{*}$ nAChRs in the mesocorticolimbic dopaminergic system. (A) The structure of mesocorticolimbic circuitry, and the distributions of $\alpha 6 *$ nAChRs. (B) Within the VTA, $\alpha 6^{*}$ nAChRs express on DA neuronal somato, and GABAergic terminals/boutons synapsing on DA neurons and GABA neurons.

(ACh) itself when nAChRs are activated (or desensitized). nAChRs are also expressed on neuronal somatodendritic regions, where they presumably modulate neuronal excitability directly. Therefore, EtOH reward and dependence through nAChRs involved these pre- and post-synaptic mechanisms. On one hand, $\mathrm{EtOH}$ alters cholinergic modulations in neurotransmitter releases in the mesolimbic pathway. On the other hand, EtOH directly modulates nAChR expression, up or down regulation, and functions such as allosteric modulation, stabilization, desensitization or internalization ${ }^{[37]}$. Through these mechanisms, EtOH enhances mesolimbic DA signaling and consequently triggers reward and dependence. For example, systemic EtOH-induced DA release in the rat NAc. This DA release was completely abolished by nAChR antagonist, mecamylamine ${ }^{[17]}$. Interestingly, only perfused mecamylamine in the VTA, but not in the NAc, prevented the accumbal DA overflow after systemic $\mathrm{EtOH}^{[38]}$. The voluntary $\mathrm{EtOH}$ self-administration demonstrated an increase in DAergic and cholinergic neurotransmission ${ }^{[39]}$, suggesting that VTA nAChRs may play an important role in mediating the mesolimbic activating and reinforcing properties of $\mathrm{EtOH}^{[40]}$. During in vitro preparations, EtOH potently modulates nAChRs at low concentrations $(100 \mu \mathrm{mol} / \mathrm{L}-10 \mathrm{mmol} / \mathrm{L})$, suggesting nAChRs as potential targets for $\mathrm{EtOH}$ action ${ }^{[41]}$. In Xenopus oocytes, acute $\mathrm{EtOH}(75 \mathrm{mmol} / \mathrm{L})$ potentiated AChinduced current of $\alpha 2 \beta 4$, $\alpha 4 \beta 4, \alpha 2 \beta 2$, and $\alpha 4 \beta 2 \mathrm{nAChRs,} \mathrm{while}$ lower concentrations of EtOH (20-50 mmol/L) inhibited nicotine-induced current of $\mathrm{a} 7 \mathrm{nAChRs}$ and all concentrations of $\mathrm{EtOH}$ tested have no effect on a3 $\beta 2$ or a3 $\beta 4 \mathrm{nAChRs}{ }^{[42]}$. In cultured cortical neurons, EtOH potentiated non-a7 nAChRbut inhibited a7 nAChR-mediated currents ${ }^{[43]}$. In brain slices $^{[44]}$ or isolated neurons ${ }^{[45]}, \mathrm{EtOH}$ excited VTA DAergic neurons and increased neuronal firing rate. Taken together, $\mathrm{EtOH}$ directly and/or indirectly modulates $\mathrm{nAChR}$ functions, which in turn alters mesolimbic function, and leads to reward and dependence.

\section{nAChR-associated ligands as a new therapeutic strategy to treat alcoholism}

There have been three FDA approved medications for treating alcoholism; (1) Disulfiram, approved in 1954, is an acetaldehyde dehydrogenase inhibitor which improves alcohol symptoms such as headache, nausea, vomiting, weakness, mental confusion, or anxiety ${ }^{[46]}$. (2) Naltrexone, available since 1994, is a competitive opioid receptor antagonist that works by decreasing the euphoric effects produced by alcohol ${ }^{[47]}$. (3) Acamprosate is a partial agonist of NMDA receptors and an antagonist of metabotropic glutamate receptors and is thought to act as an anti-craving medication by inhibiting glutamate signaling ${ }^{[48]}$. Unfortunately, only $20 \%-30 \%$ of treated patients respond positively to these drugs ${ }^{[49]}$ and some of these drugs have shown serious negative side effects. Thus, there is an urgent need to develop new drugs for the treatment of alcoholism. Recently, nAChR-associated ligands have been shown as potential candidates for this purpose. For example, pharmacotherapeutic targeting $\mathrm{nAChRs}$ such as cytisine, sazetidine A, varenicline, lobeline mecamylamine, PF-4575180 and CP-601932 are the new strategies to treat alcohol dependence including reducing voluntary alcohol consumption or modulating alcohol drinking behavior in animal models and humans ${ }^{[50]}$.

In conclusion, alcoholism is a complex disorder which alters many brain functions. EtOH induces an array of neuronal functions. The action of EtOH on nAChRs in the mesolimbic pathway marks these receptors as important for $\mathrm{EtOH}$ reward and dependence. Current evidence establishes nAChRs as new and promising pharmacological targets in the development of new drugs for the treatment of alcoholism.

\section{References}

1 Mokdad AH, Marks JS, Stroup DF, Gerberding JL. Actual causes of death in the United States, 2000. JAMA 2004; 291: 1238-45.

2 World Health Organization Editors. Global status report on noncommunicable diseases. Geneva, Switzerland: World Health Organization; 2010. 
3 (CASA) TNCoAaSA Shoveling Up II: The impact of substance abuse on federal, state, and local budgets. New York, NY: Columbia University; 2009.

4 Gilpin NW, Koob GF. Neurobiology of alcohol dependence: focus on motivational mechanisms. Alcohol Res Health 2008; 31: 185-95.

5 Mukamal KJ, Conigrave KM, Mittleman MA, Camargo CA Jr, Stampfer MJ, Willett WC, et al. Roles of drinking pattern and type of alcohol consumed in coronary heart disease in men. N Engl J Med 2003; 348 : 109-18.

6 Mukamal KJ, Maclure M, Muller JE, Mittleman MA. Binge drinking and mortality after acute myocardial infarction. Circulation 2005; 112 : 3839-45.

7 Wise RA, Rompre PP. Brain dopamine and reward. Annu Rev Psychol 1989; 40: 191-225.

8 Morikawa H, Morrisett RA. Ethanol action on dopaminergic neurons in the ventral tegmental area: interaction with intrinsic ion channels and neurotransmitter inputs. Int Rev Neurobiol 2010; 91: 235-88.

9 Li D, Sulovari A, Cheng C, Zhao H, Kranzler HR, Gelernter J. Association of gamma-aminobutyric acid a receptor $\alpha 2$ gene (GABRA2) with alcohol use disorder. Neuropsychopharmacology 2013; doi: 10.1038/ npp.2013.291.

10 Wise RA. Addictive drugs and brain stimulation reward. Annu Rev Neurosci 1996; 19: 319-40.

11 Ayers J, Ruff CF, Templer DI. Alcoholism, cigarette smoking, coffee drinking and extraversion. J Stud Alcohol 1976; 37: 983-5.

12 Gotti C, Clementi F. Neuronal nicotinic receptors: from structure to pathology. Prog Neurobiol 2004; 74: 363-96.

$13 \mathrm{Wu}$ J, Lukas RJ. Naturally-expressed nicotinic acetylcholine receptor subtypes. Biochem Pharmacol 2011; 82: 800-7.

14 Wu J, Liu Q, Yu K, Hu J, Kuo YP, Segerberg M, et al. Roles of nicotinic acetylcholine receptor beta subunits in function of human alpha4containing nicotinic receptors. J Physiol 2006; 576: 103-18.

15 Klink R, de Kerchove d'Exaerde A, Zoli M, Changeux JP. Molecular and physiological diversity of nicotinic acetylcholine receptors in the midbrain dopaminergic nuclei. J Neurosci 2001; 21: 1452-63.

16 Shytle RD, Silver AA, Lukas RJ, Newman MB, Sheehan DV, Sanberg PR. Nicotinic acetylcholine receptors as targets for antidepressants. Mol Psychiatry 2002; 7: 525-35.

17 Blomqvist O, Engel JA, Nissbrandt H, Soderpalm B. The mesolimbic dopamine-activating properties of ethanol are antagonized by mecamylamine. Eur J Pharmacol 1993; 249: 207-13.

18 Blomqvist O, Ericson M, Johnson DH, Engel JA, Soderpalm B. Voluntary ethanol intake in the rat: effects of nicotinic acetylcholine receptor blockade or subchronic nicotine treatment. Eur J Pharmacol 1996; 314: 257-67.

19 Löf E, Olausson P, deBejczy A, Stomberg R, McIntosh JM, Taylor JR, et al. Nicotinic acetylcholine receptors in the ventral tegmental area mediate the dopamine activating and reinforcing properties of ethanol cues. Psychopharmacology 2007; 195: 333-43.

20 Kuzmin A, Jerlhag E, Liljequist S, Engel J. Effects of subunit selective nACh receptors on operant ethanol self-administration and relapse-like ethanol-drinking behavior. Psychopharmacology 2009; 203: 99-108.

21 Hendrickson LM, Zhao-Shea R, Tapper AR. Modulation of ethanol drinking-in-the-dark by mecamylamine and nicotinic acetylcholine receptor agonists in C57BL/6J mice. Psychopharmacology 2009; 204: 563-72.

22 Farook JM, Lewis B, Gaddis JG, Littleton JM, Barron S. Effects of mecamylamine on alcohol consumption and preference in male C57BL/6J mice. Pharmacology 2009; 83: 379-84.

23 Liu L, Zhao-Shea R, McIntosh JM, Tapper AR. Nicotinic acetylcholine receptors containing the alpha 6 subunit contribute to ethanol activation of ventral tegmental area dopaminergic neurons. Biochem Pharmacol 2013; 86: 1194-200.

24 Bhutada P, Mundhada Y, Ghodki Y, Dixit P, Umathe S, Jain K. Acquisition, expression, and reinstatement of ethanol-induced conditioned place preference in mice: effects of exposure to stress and modulation by mecamylamine. J Psychopharmacol 2012; 26: 315-23.

25 Ericson M, Molander A, Lof E, Engel JA, Soderpalm B. Ethanol elevates accumbal dopamine levels via indirect activation of ventral tegmental nicotinic acetylcholine receptors. Eur J Pharmacol 2003; 467: 85-93.

26 Larsson A, Jerlhag E, Svensson L, Soderpalm B, Engel JA. Is an alphaconotoxin MII-sensitive mechanism involved in the neurochemical, stimulatory, and rewarding effects of ethanol? Alcohol 2004; 34: 239-50.

27 Kamens HM, Andersen J, Picciotto MR. Modulation of ethanol consumption by genetic and pharmacological manipulation of nicotinic acetylcholine receptors in mice. Psychopharmacology 2010; 208: 613-26.

28 Kamens HM, Hoft NR, Cox RJ, Miyamoto JH, Ehringer MA. The alpha6 nicotinic acetylcholine receptor subunit influences ethanol-induced sedation. Alcohol 2012; 46: 463-71.

29 Santos N, Chatterjee S, Henry A, Holgate J, Bartlett SE. The alpha5 neuronal nicotinic acetylcholine receptor subunit plays an important role in the sedative effects of ethanol but does not modulate consumption in mice. Alcohol Clin Exp Res 2013; 37: 655-62.

30 Hendrickson LM, Zhao-Shea R, Pang X, Gardner PD, Tapper AR. Activation of alpha4* nAChRs is necessary and sufficient for vareniclineinduced reduction of alcohol consumption. J Neurosci 2010; 30: 10169-76.

31 Bierut LJ, Schuckit MA, Hesselbrock V, Reich T. Co-occurring risk factors for alcohol dependence and habitual smoking. Alcohol Res Health 2000; 24: 233-41.

32 Landgren S, Engel JA, Andersson ME, Gonzalez-Quintela A, Campos $J$, Nilsson $\mathrm{S}$, et al. Association of nAChR gene haplotypes with heavy alcohol use and body mass. Brain Res 2009; 1305: S72-9.

33 Taylor DH, Steffensen SC, Wu J. Nicotinic acetylcholine receptors in the ventral tegmental area are important targets for nicotine and ethanol co-dependence. Biochem Pharmacol 2013; doi:10.4172/2167-0501.S1-002.

34 Role LW, Berg DK. Nicotinic receptors in the development and modulation of CNS synapses. Neuron 1996; 16: 1077-85.

35 Taylor DH, Burman PN, Hansen MD, Wilcox RS, Larsen BR, Blanchard $\mathrm{JK}$, et al. Nicotine enhances the excitability of gaba neurons in the ventral tegmental area via activation of alpha 7 nicotinic receptors on glutamate terminals. Biochem Pharmacol 2013; S1-007.

36 Wonnacott S. Presynaptic nicotinic ACh receptors. Trends Neurosci 1997; 20: 92-8.

37 Dopico AM, Lovinger DM . Acute alcohol action and desensitization of ligand-gated ion channels. Pharmacol Rev 2009; 61: 98-114.

38 Blomqvist O, Ericson M, Engel JA, Soderpalm B. Accumbal dopamine overflow after ethanol: localization of the antagonizing effect of mecamylamine. Eur J Pharmacol 1997; 334: 149-56.

39 Nestby P, Vanderschuren LJ, De Vries TJ, Mulder AH, Wardeh G, Hogenboom $\mathrm{F}$, et al. Unrestricted free-choice ethanol self-administration in rats causes long-term neuroadaptations in the nucleus accumbens and caudate putamen. Psychopharmacology 1999; 141: 307-14.

40 Ericson M, Blomqvist O, Engel JA, Soderpalm B. Voluntary ethanol intake in the rat and the associated accumbal dopamine overflow are blocked by ventral tegmental mecamylamine. Eur J Pharmacol 1998; 358: 189-96.

41 Nagata K, Aistrup GL, Huang CS, Marszalec W, Song JH, Yeh JZ, et al. 
Potent modulation of neuronal nicotinic acetylcholine receptor-channel by ethanol. Neurosci Lett 1996; 217: 189-93.

42 Cardoso RA, Brozowski SJ, Chavez-Noriega LE, Harpold M, Valenzuela $\mathrm{CF}$, Harris RA. Effects of ethanol on recombinant human neuronal nicotinic acetylcholine receptors expressed in Xenopus oocytes. J Pharmacol Exp Ther 1999; 289: 774-80.

43 Aistrup GL, Marszalec W, Narahashi T. Ethanol modulation of nicotinic acetylcholine receptor currents in cultured cortical neurons. Mol Pharmacol 1999; 55: 39-49.

44 Brodie MS, Shefner SA, Dunwiddie TV. Ethanol increases the firing rate of dopamine neurons of the rat ventral tegmental area in vitro. Brain Res 1990; 508: 65-9.

45 Brodie MS, Appel SB. The effects of ethanol on dopaminergic neurons of the ventral tegmental area studied with intracellular recording in brain slices. Alcohol Clin Exp Res 1998; 22: 236-44.
46 Christensen JK, Moller IW, Ronsted P, Angelo HR, Johansson B. Doseeffect relationship of disulfiram in human volunteers. I: Clinical studies. Pharmacol Toxicol 1991; 68: 163-5.

47 Volpicelli JR, Alterman Al, Hayashida M, O'Brien CP. Naltrexone in the treatment of alcohol dependence. Arch Gen Psychiatry 1992; 49: 876-80.

48 Mason BJ, Goodman AM, Chabac S, Lehert P. Effect of oral acamprosate on abstinence in patients with alcohol dependence in a doubleblind, placebo-controlled trial: the role of patient motivation. J Psychiatr Res 2006; 40: 383-93.

49 Spanagel R. Alcoholism: a systems approach from molecular physiology to addictive behavior. Physiol Rev s 2009; 89: 649-705.

50 Rahman S, Prendergast MA. Cholinergic receptor system as a target for treating alcohol abuse and dependence. Recent Pat CNS Drug Discov 2012; 7: 145-50. 